\title{
A inCIDÊnCIa REAL da CaUSa na PSICANálise
}

\author{
Fernanda Costa-Moura
}

\begin{abstract}
RESUMO
O artigo trata da articulação da noção de causa na psicanálise a partir do Seminário A Angústia de Lacan e de referências feitas ao problema da causalidade em Kant naquele contexto. Busca-se identificar na função da causa a dimensão ontológica que Lacan relaciona ao conceito freudiano de inconsciente. Aborda-se a elaboração do objeto $a$, causa do desejo, a partir dos elementos da pulsão, para analisar qual foi, e para o que aponta a revisão do problema da causalidade proposta por Lacan. Concluindo por meio da indicação de que o que muda com a introdução da causa no campo do sujeito é a própria noção de causa.
\end{abstract}

Palavras-chave: Causa. Real. Sujeito. Objeto a.

\section{THE REAL INCIDENCE OF THE CAUSE IN PSYCHOANALYSIS}

\begin{abstract}
The concept of cause developed in Lacan's Seminar On Anguish is examined in the context of the landmark contribution to the philosophical discussion on causality that is brought by Kant and argued by Lacan. We investigate the ontological dimension of causality that Lacan relates to the Freudian notion of Unconscious. In this direction, the article aims at the structure of the object "petit $a$ ", cause of the desire, as it derives from the elements of the drive, to show the importance of Lacan's formulations of the cause and to indicate that this process touches and transforms not only the field of the subject but the concept of cause itself.
\end{abstract}

Keywords: Cause. Real. Subject. Object "petit a".

Em artigo de 1964, Lacan, constatando a característica intermitente que ele chama de "sésamo do inconsciente" - a saber, que o inconsciente depende de um efeito de fala (de palavra) que se presentifica, ou não -, comenta que esse mesmo

^ Psicanalista membro do Tempo Freudiano Associação Psicanalítica e professora do Programa de Pós-Graduação em Teoria Psicanalítica - IP/UFRJ. Financiamento: Faperj (Bolsa de Fixação de Pesquisador). Programa de Pós-Graduação em Teoria Psicanalítica - IP/UFRJ. Pontifícia Universidade Católica do Rio de Janeiro - Departamento de Psicologia. CNPq (Bolsa de Doutorado). Endereço: R. Bernardino dos Santos, 37, Santa Teresa, Rio de Janeiro - RJ, CEP 20241-000. E-mail: fcostamoura@infolink.com.br 
traço obriga os analistas a refletirem sobre o modo e o fato desse fechamento. É essa intermitência (abertura versus fechamento) do inconsciente, já constatada por Freud, que nos dá, diz Lacan, a chave do seu espaço e da impropriedade em que incorremos "se queremos fazer dele um dentro" (LACAN, 1998, p. 838). Mas, acima de tudo, continua Lacan:

[...] a experiência deste fechamento mostra que não seria um ato gratuito para os psicanalistas reabrir o debate sobre a causa, fantasma impossível de conjurar do pensamento, crítico ou não. Pois a causa não é [...] um logro das formas do discurso - já se o teria dissipado. Ela perpetua a razão que subordina o sujeito ao efeito do significante (LACAN, 1998, p. 839).

É dessa posição, que pode ser tomada como uma exortação eloqüente feita aos analistas, que Lacan discorrerá durante um longo período de seu ensino, e às vezes por meio de pequenos, contundentes e enigmáticos aforismos, sobre a noção de causa. De uma posição em que recorrer à noção de causa corresponde a, nada mais nada menos, que, como ele diz no Seminário XI, "fazer apreender o inconsciente, conceito freudiano" (LACAN, 1981 p. 26) - e apreendê-lo, a partir da noção de causa, não como lugar, superfície, entidade ("um dentro"), mas como efeito da linguagem; em particular, do significante (LACAN, 1981, p. 26).

Porém, pensar a causalidade não é tarefa simples. Percorrendo minimamente a literatura filosófica sobre o assunto, vê-se que há inúmeros modos de colocar esse problema, cada um com um certo número de implicações e conseqüências peculiares, e todos deixando, de alguma maneira, um resto que incita a retomá-lo. Desse fantasma talvez se possa dizer que sua principal função na história do pensamento filosófico é sobreviver, arrastando por milênios um problema sem solução.

Na tentativa de situar a especificidade da causalidade que Lacan (2005) articula, optei por circunscrever este trabalho ao remanejamento imposto à causalidade no contexto de seu seminário A Angústia - aí incluídas, também, as referências feitas ao problema da causalidade concebido por Kant, seu papel nos avanços e crises da razão - como forma de considerar os termos em que se registra o equacionamento de tal problema na psicanálise.

Mesmo assim, ou, justo por isso, encontrei-me na incômoda posição de ter de tentar encaminhar uma discussão a partir da perspectiva forçosamente parcial que a leitura de Lacan do que foi o problema de Kant implica -, sem poder oferecer, neste contexto, um corpo de documentação (em nível de referências, demonstrações, contextualizações etc.) que pudesse indicar mais consistentemente a majestade da catedral erigida por Kant em torno do problema da causa. Enfim, após lutar com a história da filosofia e das ciências - impossíveis de reduzir ao âmbito deste trabalho - só posso nesse contexto dar algumas indicações sobre as contribuições, tanto de Kant quanto de Lacan, ao problema da causa e à forma como o campo psicanalítico se encontra com elas relacionado. 


\section{Celeuma}

A noção de causa tem sido, ao longo dos séculos, redefinida a partir de diversas posições e diferentes perspectivas de interesse. E, por outro lado, essas redefinições (que constituem as diversas concepções de causalidade) têm sido elas mesmas objeto da filosofia. Percorrendo a literatura, entretanto, percebe-se que, nos vários modos de colocar o problema da causalidade, a divisão e literal separação efetuada por Kant no período crítico entre causalidade ontológica e causalidade como problema referido exclusivamente ao registro do conhecimento (causalidade científica) persiste, ainda hoje, de algum modo intocada. A dimensão ontológica envolvida na causalidade - a causação, nome dado ao ato de causar, ou antes, o problema que é colocado quando se entende a relação causa efeito como alguma coisa a mais (ou diferente) do que uma simples sucessão (associação) - é recuada ao infinito, ou abandonada, embora esteja em jogo, de um jeito ou de outro, nas discussões sobre causalidade.

Alquié (1982) mostra, em A idéia de Causalidade de Descartes a Kant, que essa passagem da causalidade como problema ontológico a problema do conhecimento é correlata à passagem de uma concepção analítica da causa (na qual esta era considerada como uma relação racional de dedutibilidade do efeito a partir de sua causa) a uma concepção sintética (na qual causa e efeito estão unidos por um liame acrescentado e que permanece exterior aos seus termos). Do artigo de Alquié se pode também inferir os vários modos que o pensamento encontrou de contornar esse problema ou enfrentá-lo. Na chamada concepção analítica da causalidade (em Descartes, mas presente de certa forma desde Aristóteles), a causação é vista como um dado natural - o que é uma forma bastante eficaz de renunciar ao problema. Por outro lado, numa concepção sintética, a interrogação sobre a causalidade deixa de lado, como problemático, o plano ontológico, para se preocupar apenas com o plano do conhecimento. A conseqüência é a separação de planos entre a causalidade como problema ontológico - que Kant (2000), no pensamento crítico faz recair sobre o plano da moral como liberdade - e a causalidade tomada do ponto de vista do problema do conhecimento (causalidade científica).

Foi a partir de Hume (1999), que desnaturaliza a causa demonstrando sua ininteligibilidade, que se produziu essa modificação radical na maneira de colocar o problema da causalidade. Modificação que determinou a substituição do problema ontológico como interrogação sobre o ser pelo problema relativo à ordem do conhecimento. Mas essa divisão é retomada por Kant, que faz dela a pedra de toque de seu pensamento (e não apenas de seu pensamento sobre a causalidade).

Inicialmente, no período pré-crítico, alertado pelos novos encaminhamentos da física e pelo trabalho de Hume para o problema central da incompreensibilidade metafísica da relação causal (incompreensibilidade que concerne a uma relação real), Kant redireciona seu trabalho para a separação irredutível existente entre o lógico e o real. Coloca-se então para Kant o problema de formular uma existência que não é mais vista como atributo de nenhuma essência, e sim como "posição absoluta" (positio), existência. Trata-se da diferença 
entre o ser da cópula lógica e o da posição, da existência - Wirklichkeit, presença pura, irredutível a todo formalismo lógico.

Essa nova ontologia, que reconhece à Wirklichkeit um estatuto específico, radicalmente irredutível ao lógico, restitui à questão da causalidade seu sentido de questão ontológica fundamental. O Ensaio para introduzir em filosofia o conceito de Grandeza Negativa (KANT, 1972) refletirá essa posição. Aplicando ao problema da oposição de forças (e fatores) a distinção lógico/real, extrai disso a especificidade da oposição real. A grandeza negativa, nos diz Kant, não é uma negação de grandeza. Ela é grandeza, isto é, valor, diferença, elemento variável, suscetível de tornar-se grandeza negativa, apesar de ser real, simplesmente porque oposto a outra grandeza positiva. Para a idéia de grandeza negativa, portanto, a relação é essencial. Uma grandeza negativa não existe isoladamente. De modo que, nesse caso, se estabelece uma antinomia entre o ser e o sentido, antinomia que se está fadado a reencontrar efetivamente como distância (afastamento, separação, irredutibilidade) entre o lógico e o existente.

Foi isso o que Hume teria constatado como a ilogicidade da causa, ao se deparar com a questão de que a relação do princípio à conseqüência é radicalmente distinta da relação da causa ao efeito (DELEUZE, 1998). Do mesmo modo, o problema da causalidade no Ensaio é visto por Kant como se oferecesse uma dificuldade a toda apreensão conceitual impossível de ser racionalizada e expressa num juízo (KANT, 1972, p. 62). Não se chega à causa por meio de um juízo (que é síntese) - porque ela reúne inconciliáveis - e também não se chega por análise, posto que esta, no caso da causa, é infinita (a causa tem de ser sempre desdobrada em conceitos analíticos mais restritos, sem que nenhum possa recobrir todo seu campo de influência). A causa sendo uma relação entre coisas diferentes, enfeixa um problema que ultrapassa aquele da lógica formal. Nesse sentido, a causa, mais que uma noção, designa uma hiância, na medida em que aparece como conceito inanalisável, que só podemos constatar. Por outro lado, a existência das grandezas negativas mostra que a causa, como grandeza negativa, não é um nada. Embora a razão não possa designá-la a não ser pelo negativo, a causa não é simplesmente ausência de um princípio positivo, ela é - positio, Wirklichkeit - real.

No período pré-crítico (mais próximo a Hume), a tarefa da filosofia é vista por Kant como uma censura, trabalho de fixar as fronteiras negativas do pensamento. No período crítico, além desse lado negativo ela se exerce também numa direção positiva, devendo indicar o a priori transcendental - que substitui o $a$ priori metafísico como condição de possibilidade do conhecimento. Nessa passagem para a filosofia crítica, a questão de Hume é transmutada da oposição lógico/ real para a relação da representação (vale dizer, do sujeito) ao objeto. Questão que a filosofia crítica pleiteia ultrapassar.

A solução proposta por Kant no contexto do pensamento crítico para o problema da representação do objeto consiste, como sabido, em uma mudança na própria questão. Em vez de perguntar se o conhecimento cientifico é possível, questionar sua possibilidade, Kant parte do conhecimento como um fato e a partir daí se dirige para examinar como ele é possível, qual a sua legalidade. Essa torção 
na interrogação fundamental sobre o conhecimento dará nascimento a uma nova lógica, a lógica transcendental, da qual a lógica formal será apenas uma expressão possível. A questão de uma harmonia entre sujeito e objeto será reformulada em termos de possibilidade da objetividade do conhecimento, e será pensada no âmbito do próprio pensamento que conhece. A partir da crítica kantiana e, para sempre, muda nossa concepção do conhecimento do real. Conforme Philonenko: “o que é real, o que é verdadeiro, o que é objetivo, no sentido crítico do termo, passa a ser, não o ser sensível como um aqui-e-agora, mas o que é constante, durável, existente no nosso conhecimento" (PHILONENKO, 1989, p. 106) - ou nos termos consagrados pelo próprio Kant (1989), universal e necessário.

A partir desse passo, Kant afirma que a necessidade e universalidade presentes nos juízos científicos são obtidas pela síntese das diferentes faculdades em jogo na razão (sensibilidade, entendimento e imaginação). Pela analítica transcendental, chega-se então às formas a priori do entendimento, entre as quais está a causalidade entendida como logicamente anterior à experiência. Percebemos a causalidade porque a razão sintetiza "um princípio de sucessão no tempo com a lei da causalidade" (KANT, 1989, p. 217). A causalidade não está contida no fenômeno, mas lhe é aplicada pelo entendimento por meio da categoria de relação (efeito/causa) que então constitui o próprio fenômeno como tal. ${ }^{1}$

A ordem absoluta (incondicionada), que é a oposição real, será recuada ainda no contex to da primeira Crítica para a noção de numeno - que é suspendida como problemática e aparece na bela e engenhosa construção de Kant como "conceito limite" ou "idéias reguladoras". Tais idéias constituem inevitavelmente o "conflito da razão" entre o "desespero céptico" e a "obstinação dogmática" (KANT, 1989, p. 380). Antitéticas, elas são "idéias que não se podem conciliar com os fenômenos" (KANT, 1989, p. 380). Não obstante, as idéias reguladoras da razão são importantes para o conhecimento, porque retroativamente elas agem sobre o entendimento, exigindo deste uma unidade ainda mais ampla, em direção ao "limite" da experiência possível. São postuladas como "conceito limite" por Kant por terem a função de "cercear a pretensão da sensibilidade [de se estender a tudo o que o pensamento pensa]" (KANT, 1989, p. 381), prestando-se, portanto, a um "uso negativo". Assim, embora não se possa conhecê-las, pode-se e deve-se pensálas. O plano ontológico que restara como problemático na primeira Crítica, adquire agora, ainda que sob um fundo hipotético (não se pode ter certeza apodítica desse plano), o estatuto de um campo Outro - que será o da razão prática, campo da moral.

Kant vê aí a abertura para um novo alcance da Crítica. Mas para a discussão que se trava aqui, o mais importante é ressaltar que a passagem só pode se consumar num outro plano que não o do conhecimento - plano da moral, que é requerido pelo fato de as antinomias em questão serem estruturadas por uma tensão (tese e antítese) que o pensamento cognoscente não é capaz de pacificar. A liberdade, por exemplo, é a liberdade de se submeter ao imperativo moral. Ela não pode ser conhecida e sim constatada pelo sujeito do imperativo categórico, como fato da razão. E, nesse sentido, ao menos por um momento, Kant sustenta o hiato, a passagem a um outro registro, digamos, que tal tensão implica. Trata-se do corte na 
continuidade do pensamento, abismo da representação, que constituirá a "Outra Cena" a qual Freud encontra igualmente, mas num contexto inteiramente diferente desse da especulação filosófica, ao escutar as escaramuças amorosas de suas primeiras pacientes.

Para Freud, abordar o que é fundamentalmente fenda, o que é descontinuidade era também o problema com o inconsciente: como abordá-lo sem reificá-lo, sem reverter sua negatividade operante numa positividade apreensível? Nesse sentido, enfrentar a dificuldade que coloca o problema da causa era o mesmo que (era talvez um modo de) tentar articular o inconsciente em sua estrutura lacunar - por isso, o movimento freudiano reintroduz, na psicanálise, a questão da causa. À medida que avança, Freud tenta criar um arcabouço (é o que ele chama "aparelho psíquico") que possa cernir, apreender, evidenciar, materializar algo desta dimensão da existência dos sujeitos a que ele tinha tido acesso. Porém, ao fazê-lo, inevitavelmente ele se depara com o corte que isso representa.

Na discussão do caso clínico de Fräulein Elizabeth Von R., o quinto dos cinco publicados em Estudos Sobre Histeria (1976), depois de escrever "Eis aqui, portanto, a infeliz história dessa moça orgulhosa que queria amor", frase com a qual ele começa finalmente a poder elucidar o que "por muito tempo", nas suas próprias palavras, "fora incapaz de apreender" (isto é: "a conexão entre os fatos de sua doença e os sintomas reais, que, não obstante, devem ter sido causados por aquele conjunto de experiências"), Freud se queixa:

Nem sempre fui psicoterapeuta. Como outros neuropatologistas, fui preparado para empregar diagnósticos locais e eletroprognose e ainda me surpreende que as histórias [casos] clínicas por mim descritas pareçam romances de folhetim e que delas esteja ausente, por assim dizer, o selo de seriedade que o científico leva estampado. Por este fato, tenho que me consolar dizendo que o responsável por este resultado é a natureza mesma do assunto, mais que alguma predileção minha. $\mathrm{O}$ fato é que o diagnóstico local e as reações elétricas não levam a parte alguma no estudo da histeria (FREUD, 1976, p. 174).

Freud resiste e não é à toa. A causalidade circunscrita pela psicanálise pode nos atingir, ainda hoje, com um estranhamento semelhante ao que atingiu Hume ou Kant quando se propuseram o problema da causa - há um descompasso: o efeito não está contido na causa, a consequiência não está contida no princípio. É impossível compreender, em princípio, qual é a relação da causa com o efeito. Há algo aí que faz obstáculo à razão, que não se deixa reduzir ao funcionamento em termos de identidade ou contradição.

Porém, a solução freudiana perante o problema da causa - solução original que advém em função da perspectiva de interesse que é a de Freud, uma perspectiva clínica, operatória - consiste em afirmar o impasse que encontrou. A psicanálise, pode-se dizer, é justamente a explicitação desse embaraço (que a causa sem- 
pre foi) como limite, impossibilidade de saber; por meio do que se atinge não só o inconsciente como o desejo numa instância decisiva.

No auge do impasse com a causa, o esforço de Freud criou toda uma gama de noções que marcaram nosso século, modificando nossa visão das coisas. Seu embaraço e o constrangimento com a questão da causa sinalizam não uma ineficiência, mas, antes, são índice de um campo novo, um campo fundado sobre outros conceitos mais fundamentais do que aqueles a partir dos quais a filosofia e a ciência vêm falar. Campo que se abre no discurso e para o sujeito - a psicanálise.

Por enfeixar esse limite da razão e do discurso, a causalidade articulada por Lacan a partir da experiência de Freud retomará os dois tipos de discussão que estavam muito bem separados desde Kant: o da causalidade ontológica e o da causalidade científica - reunindo novamente as duas celeumas.

\section{NA DIREÇÃo dA ABERTURA DA ANGÚSTIA}

Já em 1956, Lacan afirmava que, por ter decifrado a estrutura significante do sintoma, Freud ligou a questão da causalidade à incidência da verdade como causa, introduzindo a questão da causalidade por um "acesso inteiramente novo" (LACAN, 1966, p. 417) e que impõe uma revisão do processo de causalidade. Revisão cuja primeira etapa consistiria justamente no reconhecimento freudiano da onipotência da função simbólica para o ser humano.

Alguns anos mais tarde, Lacan, ele mesmo, viria a empreender mais um passo dessa "revisão", efetuando a passagem de uma concepção da causalidade articulada pelo significante à causalidade entendida como resto da articulação significante - por conta da qual, a problemática da causa em seu ensino desloca-se do significante e das leis da linguagem para o objeto como "heteros". A ocasião compreende sobretudo seus Seminários: A Angústia, proferido em 1962 e 1963, e Os quatro conceitos fundamentais da psicanálise, realizado durante o ano de 1964, embora os remanejamentos da noção de causa estejam sempre presentes e reivindicados até o fim de seu ensino.

O Seminário A Angústia (LACAN, 2005) é um marco. Ele introduz o que Lacan chama sua única invenção - o objeto $a$-, aproximando-o da função da causa. Retornando com isso à secular querela filosófica e científica que marca a noção de causa e que se passa tradicionalmente no plano do conhecimento, em torno de vários tipos de solução para o problema da causa, que tendem a uma redução da noção ou de sua importância. Na contramão desse movimento, vê-se Lacan nesse Seminário retomar a noção de causa, promovendo seu aproveitamento na psicanálise e incitando à sua revalorização.

Na lição de 19/12/1962 do mesmo Seminário X, Lacan situa a angústia como o "corte nítido sem o qual a presença do significante, seu funcionamento, seu sulco no real é impensável". Argumenta nesse ponto que a função da causalidade está em outro lugar do que onde se a refuta. E avança: "se há uma dimensão em que devemos buscar a verdadeira função, o verdadeiro peso, o sentido da ma- 
nutenção da função de causa é na direção da abertura da angústia" (LACAN, 2005, p. 88).

É uma formulação surpreendente. E é sobretudo em torno do que ela traz que se pode apreender o que existe, na obra e no ensino de Lacan, de subversão da problemática da causa. Lacan evoca e situa, com sua afirmação, o domínio em que tradicionalmente se dá o debate sobre a causalidade, domínio do conhecimento, da razão, da objetividade - com as implicações próprias desse terreno que ele reconhece quando diz que o problema da causa aí é refutado. E, por outro lado, numa reviravolta desconcertante, faz recair o problema da causa num campo inteiramente diferente. Campo, como ele dirá a seguir, "da objetalidade", que diz respeito ao corte que o significante efetua e concerne ao pathos deste corte no corpo (e não ao pensamento).

Lacan distingue a objetalidade que faz limite ao conceito da objetividade "termo supremo do pensamento científico ocidental" (LACAN, 2005, p. 236) como o correlato de uma razão pura que se articula num formalismo lógico. A objetalidade, diz Lacan, advém de um corte que é "desconhecido como tal na Crítica da Razão Pura” (LACAN, 2005, p. 237). Referindo-se possivelmente ao fato de que Kant (1781/1989) pensa a causalidade como síntese que reúne objetos numa relação (PUECH, 1990), desconhecendo, portanto, o corte - presente desde sempre na causalidade - em sua dimensão de corte ("como tal"). E, no entanto, é por esse mesmo corte que o formalismo lógico (que a Crítica da Razão Pura mostra como funciona no nível do conhecimento) atinge o que Lacan chama seu efeito. Efeito ligado a uma perda que é constitutiva do sujeito. Assim, se a causa em sua função, onde quer que se apresente, se assevera irrefutável, apesar de irredutível e quase inapreensível para a crítica, afirma Lacan, é por se tratar do corte irreversível que o significante faz incidir no corpo.

Esse deslocamento do eixo do problema recoloca a problemática da causa sob nova perspectiva. Na lição de 16/1/1963, Lacan relembra que o isolamento da noção de causa custou muito, produziu muitas dificuldades para o progresso da epistemologia, tendo sido sem distorção, sem "uma sucessão de reduções que acabam por conduzi-la à função mais tênue e mais equívoca", que a noção de causa pôde se manter no desenvolvimento da física. Porém, o que Lacan ressalta e que parece lhe interessar é que por qualquer redução a que submetamos a "função mental desta função", como ele a chama, não pode ser eliminada - "reduzida a uma espécie de sombra metafísica". Por isso, conclui Lacan, "há alguma coisa [...] que resta em torno desta função da causa"2 da qual é muito pouco dizer "que seja um recurso à intuição o que a faz subsistir" (LACAN, 2005, p.114).

Lacan aponta para o que seria o estatuto da causa, estabelecendo-o a partir do objeto do desejo. O objeto de que se trata no desejo, objeto $a$, não deve ser situado no que quer que seja de análogo à intencionalidade. Ele não está na intencionalidade do desejo. É o objeto, diz Lacan, que aparece em Freud como objeto da pulsão (Objekt), o que vale dizer que já aí - como elemento constituinte da teoria das pulsões freudiana - ele é inteiramente diferenciado do que é o seu alvo/meta (Ziel). 
Freud (1976) enfrenta, quanto ao objeto da pulsão, um impasse, o enigma relativo ao que deve ser situado no exterior (o objeto) e a satisfação, que somente se dá à medida que a tendência em questão encontra algo a considerar como constitutivo do interior do corpo. Para resolver esse enigma, é preciso, mostra-nos Lacan, conceber o objeto na função de causa, dando a ele esse lugar de objeto "exterior antes de toda interiorização" (LACAN, 2005, p. 115). Lacan vincula essa exterioridade do objeto da pulsão ("exterior que situa em $a$ ") à causa como o que pertence a uma exterioridade inassimilável e constitutiva da demarcação de um campo. Exterioridade que ele concebe com base na noção situável topologicamente, de um exterior que é anterior a qualquer interiorização (LACAN, 2005).

Assim, retomando e reformulando a trilha aberta por Hume (DELEUZE, 1953/1998), que demonstrara a causa como um exterior inassimilável para a razão, Lacan parece concluir que a causa não apenas é, como situa, por sua efetividade irrepresentável, um exterior. É uma dimensão radical de exterioridade ao sujeito. A causa é, portanto, indiscernível como tal por colocar-se num registro que é anterior ao ponto em que um sujeito pode apreender-se no campo do Outro (campo dos significantes), "num $x$ ", diz Lacan, que, sendo um significante, abre uma possibilidade de identificação ("uma forma especular qualquer") introduzindo para o sujeito a distinção do eu e do não-eu. É por situar-se nesse registro que a causa é inassimilável - e somente por aí se pode articular o inassimilável da causa.

Visto do interior da ordem simbólica, o objeto aparece como seu irredutível e constitutivo exterior - e, por isso, causa de sua incompletude ("exterior antes de toda interioridade"). Por outro lado, se se pretende "sair" da ordem simbólica para apreender o que seria o objeto "nele mesmo" e não por meio de seus distorcidos reflexos simbólicos, o objeto apresenta-se como negatividade que só se faz contar como corte.

Nossa apreensão dos objetos é correlata de uma espacialidade e temporalidade representacional. Usualmente pensamos neles no interior de um campo por assim dizer euclidiano - um campo onde as efetividades tendem a correlacionar-se com as representações numa base biunívoca (Lacan diz que os objetos são, ordinariamente para nós, especularizáveis, isto é, eles são duplicáveis na dimensão de imagem que tem a representação). Ocorre que a dimensão da causa é justamente a de uma efetividade sem imagem, uma efetividade impossível de ser representada plenamente. Essa efetividade nos afeta - o que é demonstrado pela angústia e pelo estranhamento que o pensamento experimenta diante da dimensão da causa - e nos afeta, dirá Lacan, em nosso corpo mesmo, mas ela não cabe em nenhuma identificação estável. Ela não se constitui no espaço/tempo lineares, não se localiza como entidade, não tem realmente lugar, mas, apesar disso, aparece em certos pontos privilegiados.

Com o objeto do desejo, portanto, Lacan vai situar uma causalidade que não pode ser apreendida em termos do que é proposto por Kant como formas $a$ priori da sensibilidade - tempo e espaço. Uma causalidade que não é "dentro" nem "fora". O registro em que se engendra esse objeto como causa ("exterior 
antes de toda interioridade"), não cabe na representação. O sinal que temos dele, afirma Lacan, é a angústia - "sua única tradução subjetiva" (LACAN, 2005, p. 113).

\section{SEM RELAÇão COM O TODO}

Remetendo a função da causa à tese freudiana da angústia como sinal, Lacan comenta ainda que, quando a causa "se acende", é para que o sujeito se dê conta de algo que é um desejo - "demanda que não concerne nenhuma necessidade" (LACAN, 2005, p. 169). Mais adiante ele afirma que a causa se superpõe, "é idêntica em sua função a essa parte de nós mesmos, a parte de nossa carne que permanece necessariamente presa na máquina formal" (LACAN, 2005, p. 237).

Assim, evocando o fato de que o formalismo articulado por Kant na Crítica da Razão Pura efetivamente "morde" o real, molda, ou, nos termos de Kant, "constitui o objeto da experiência possível" (PHILONENKO, 1989), Lacan lembra o efeito disso para o sujeito. Esse formalismo não seria nada para nós se ele não nos pegasse por alguma parte, ele dirá - e é uma parte da qual damos não somente a matéria e a encarnação como ser de pensamento, mas "o pedaço carnal arrancado de nós mesmos". É essa porção que circula no formalismo lógico elaborado no trabalho do significante. "Esta parte de nós mesmos, tomada na máquina formal, para sempre irrecuperável; objeto perdido nos diferentes níveis da experiência corporal onde se produz seu corte, é ela que é o suporte, o substrato autêntico de toda e qualquer função da causa" (LACAN, 2005, p. 237).

Aí está, portanto, a grande novidade introduzida por Lacan no debate sobre a causa - sua dimensão de pathos ("porção carnal", "parte de nós mesmos para sempre irrecuperável"), e de pathos do corte ("arrancada"), de um corte como mencionado, que se articula no corpo ("nos diversos níveis da experiência corporal em que se produz seu corte") pela ação do significante ("da máquina formal").

Há perda nesse corte que extirpa o objeto dando lugar ao sujeito no mesmo golpe. Esse objeto extirpado (desde sempre parcial) dá origem a um sujeito descompletado do objeto que o causa. E em torno da relação do sujeito com a ordem simbólica se colocam a dramaticidade desse corte e o apelo desse objeto perdido para o sujeito. Comenta Lacan: "o que numa máquina não advém a tempo simplesmente cai e não reivindica nada. Não é a mesma coisa no homem, a escansão está viva, e o que não adveio a tempo permanece em suspenso [...] pedindo para ser" (LACAN, 1985, p. 384).

A escansão está viva no sujeito. E, como conseqüência, o objeto $a$, longe de ser um em si da objetividade autônoma, independente do sujeito, é o seu índice "sombra do sujeito entre os objetos" (ZIZEK, 1994, p. 33). Correlato do corte irreversível que o significante articula no corpo, o objeto $a$ é um objeto negativo que só dá notícia nos cortes em que ele se marca para o sujeito. O que se representa dele é sua forma de corte anatômico em que se decalca a função de certos objetos, diz Lacan, não parciais, mas à parte (LACAN, 1998, p. 862). 
No contexto do seminário sobre A Angústia, Lacan detém-se para demonstrar que o desejo se inscreve para cada um por uma contingência corporal. Com um arguto comentário sobre a circuncisão - que estabelece como o significante engendra a marca da castração na carne com o conseqüente aparecimento do desejo do Outro -, e o "Mercador de Veneza", de Shakespeare - em torno do tema da libra exata de carne a pagar pela dívida contraída com o Outro - Lacan mostra que na dialética da causa o corpo está envolvido não ativamente, mas pelo que há aí de inerte, de extraído, separado (LACAN, 2005, p. 237-8). E observa ainda que, mais do que dizer que a parte aí não é o todo, seria preciso acentuar que com o todo ela não tem nada a ver - "joga sua partida sozinha" (LACAN, 1998, p. 857).

O modo de apreensão do desejo do Outro pelo sujeito marca as diversas formas que esse objeto toma, nos diversos níveis de estruturação do desejo. Virão para esse lugar os objetos que o sujeito perde naturalmente (seio, excrementos) e os suportes que ele encontra para o desejo do Outro (seu olhar, sua voz). E também a pulsão, no que ela é sempre pulsão parcial, como atividade de revolver esses objetos para neles resgatar, para restaurar sua perda original - via pela qual manifesta-se para o sujeito a sexualidade, a secção (LACAN, 1998, p. 863). Contudo, em seus modos de apresentar-se e causar o desejo, o objeto apenas parece nos dar o suporte do ser, pois de fato eles são apenas suportes do que se constitui não como ser, mas como causa do desejo.

Assim, por meio de uma apresentação que, embora perfeitamente verbal, é mais gráfica do que conteudística, dos diversos níveis de estruturação do objeto, o que Lacan enfatiza e mostra são as (não) correspondências, os desencontros entre o sujeito e o Outro que fazem do desejo uma abertura (que eles causam). "Se digo que o pequeno $a$ causa o desejo isso quer dizer que ele não é dele o objeto. Não é o complemento nem direto nem indireto, mas apenas essa causa [...], essa causa que causa sempre" (LACAN,1974-5 lição de 21/1/1975).

É assim com o sujeito: a causa causa sempre. A psicanálise, ao se constituir como discurso, não pode ignorar a incidência da causa e deve retomar sua função para introduzir aí o campo do sujeito. Todavia, a vinculação do sujeito à função da causa opera um redimensionamento da questão ontológica - insolúvel - em questão ética que se coloca em ato.

\section{Cessão do objeto}

Ex-timo, externo interior que ele não pode assimilar - assim é que se apresenta para o sujeito a causa do desejo. Por mais que faça, com relação à causa do desejo há sempre um abismo que o sujeito não pode reduzir, e que, no entanto, ele precisa, deve transpor, contornar. Quando a causa comparece é que se evidencia para ele o salto que ele tem a dar. Quando ela acena é que aparece a hiância, é que se apresenta a causa como tal, como inassimilável. Parte de si que se perdeu para a máquina formal.

O que emerge efetivamente desse abismo é o desejo como desejo sexual, que inclui a partilha dos sexos, corte irrecuperável, secção. É que o acesso ao objeto do desejo, objeto causa do desejo, passa pela posição do sujeito com respei- 
to ao falo. E nisso o corpo está envolvido. Trata-se, conforme aborda Lacan, de objetalidade e não de objetividade que pudesse resolver-se no domínio do pensamento.

Porém trata-se do falo como precioso objeto imaginário e não órgão real, de modo que o corpo aí envolvido é um corpo em suspensão: a relação do sujeito ao falo encena o corte, impõe a parcialidade e a intermitência. Em "Posição do inconsciente" (1998), Lacan fala em "órgão do incorporal" para designar a libido de que é feito esse objeto - estabelecido a partir do que "o organismo vem a ser, uma vez apanhado na dialética do sujeito" e que representa "a parte do ser vivo que se perde no que ele se produz pelas vias do sexo". A cada vez "essa parte de nós mesmos, irrecuperável, arrancada" (LACAN, 1998) que é a causa, coloca o sujeito em suspenso, e este tem de novo que tomar posição quanto ao seu sexo, diante da castração.

Mas a função do objeto parcial não pode ser reduzida pelo fato de sua perda - alerta Lacan -, pelo contrário, apegamo-nos a ele porque é a partir daí que se enraíza a ilusão de cosmicidade do mundo (LACAN, 1961-2). No entanto, esse objeto parcial, nunca perdido de uma vez por todas, ao ser tomado - num ato do sujeito - como objeto $a$, definitivamente perdido, libra de carne paga, efeito da castração e causa de desejo traz à luz, como diz Lacan, o ponto a-cósmico do desejo. E o sujeito surge aí nesse corte em ato do objeto. Lacan diz: "intervalo entre unha e carne" (LACAN, 1961-2).

$\mathrm{O}$ ato do sujeito com relação à causa do desejo, ato de situar o objeto em função de causa, cujo substrato (em que se dá esse ato) é o objeto que é perdido ("nos vários níveis da experiência corporal"), Lacan vai conceber, nas últimas lições do Seminário $X$, como a cessão do objeto: "trajeto simbólico" do sujeito em direção a esse seu "suplente precedente" (antes mesmo que o sujeito esteja lá), que é $a$ (LACAN, 2005, p. 340-341), que são os objetos cessíveis (os objetos suportes da causa do desejo).

O real da cessão do objeto é o que acossa e faz o impasse do sujeito diante do desejo. Para advir o sujeito tem de se destacar sob o fundo desse objeto paradoxal que não pode ser subjetivado. Esse objeto cuja simples presença envolve afanise do sujeito, outro incompossível e próximo mais próximo de sua constituição subjetiva - é por cedê-lo que o sujeito é sujeito.

Aqui se chega, por fim, a poder mostrar em que a solução de Lacan subverte a problemática tradicional da causa. Essa subversão está, a meu ver, não somente em correlacionar causa e linguagem, mas, sobretudo em apontar a causa como resto inassimilável da operação da linguagem - e não como princípio de concatenação.

A causa como resto da inserção nunca completa do sujeito na linguagem é, deste modo, a causa da divisão do sujeito e desse fato mesmo, pathos para o sujeito (aquilo com o que ele está inarredavelmente enganchado).

Entre esse Um [que todos almejamos no discurso] e esse $a$ [que nos é imposto como resto] não há nenhuma relação 
racionalmente determinável. Nenhuma proporção é captável entre o Um e o $a$. Daí resulta que não há jamais qualquer razão para que o recobrimento de um pelo outro se termine, que a diferença será tão pequena quanto se a puder figurar, que há até um limite mas que, no interior desse limite, não haverá nunca conjunção, copulação qualquer do Um para o $a$ (LACAN, 1974-75 lição de 21/1/1975).

"A diferença será tão pequena quanto se a puder configurar" e esta configuração mínima do que não pode ser recoberto inteiramente pelo significante é a causa. O objeto $a$ que viria completar o Outro tornando inscritível a relação sexual é causa - não no sentido de um ímpetus que move a cadeia, mas, pelo contrário, por ser ele o elo que falta na cadeia. Elo que, por faltar, retira-lhe o Um e faz incidir na cadeia o Un da falta e da negação.

Tal perspectiva subverte inteiramente o modo tradicional como essa problemática é colocada por situar a causa - em total separação de planos com relação ao efeito - em direção à hiância que um ato vem instaurar. Hiância entre o que será, por esse mesmo ato, o sujeito e o objeto que permanece exterior, real - causa que não se deixa apreender, que apenas "causa sempre", "causa, causando todo efeito".

Uma tal separação de planos pode ser ocasião de recuo - quando o sujeito, descobrindo que tudo o que se pode apreender da causa são os efeitos, recua, recusa o inconsciente como abertura e fica com a neurose, a cadeia dos efeitos ou de passagem, conclusão em ato, a cada vez, pela qual então a castração, da qual até então o sujeito se queixa, aparece como o rochedo a partir do qual ele pode se lançar à vida e ao fazer. É nesse ponto que uma psicanálise pode deixar as coisas.

Trata-se não apenas da causa como ruptura no pensamento, abertura, hiância em que alguma coisa acontece e em que se redescobre a característica de interrupção, de falha, que assinala o inconsciente quando emerge, mas a causa como produção real na qual se reconhece a efetividade do inconsciente, em torno de que se dispõe toda nossa vida, em todos os aspectos.

\section{Notas}

${ }^{1}$ Tanto quanto para Hume, para Kant, a causalidade é um juízo sintético, ou seja, não sendo uma mera análise de onde se deduz a consequiência do princípio, ela une dois elementos distintos, acrescentando saber. O "problema Hume" (ligação de elementos distintos) é, portanto, respondido por Kant por meio do esquematismo transcedental (agenciamento dos fenômenos pelas faculdades a priori por meio de que adquirem dignidade de leis do conhecimento) CRPu - (KANT, 1989 p. 135 et seq.).

${ }^{2}$ Esta frase, retirada da versão estabelecida por J.A. Miller, que consta aqui conforme em LACAN (2005), encontra-se na lição de 16/1/1963 do Seminário A Angústia.

\section{REFERÊNCIAS}

ALQUIÉ, F. A idéia de causalidade de Descartes a Kant. In: CHÂTELET, F. (Org.). História da Filosofia. Rio de Janeiro: J. Zahar, 1982. v. IV. 
DELEUZE, G. Empirisme et subjectivité. Paris: PUF, 1953/1998.

FREUD, S.; BREUER, J. Estudos sobre histeria. [1893-95]. In: Obras psicológicas completas. Rio de Janeiro: Imago, 1976. E.S.B. v. II.

FREUD, S. Os instintos e suas vicissitudes. [1915]. In: . Obras psicológicas completas. Rio de Janeiro: Imago, 1976. E.S.B. v. XIV.

. Novas conferências introdutórias sobre psicanálise: Conferência XXXII: ansiedade e vida instintual. [1932]. In: Rio de Janeiro: Imago, 1976. E.S.B. v. XXII. . Obras psicológicas completas.

HUME, D. Uma investigação sobre o entendimento humano. [1748]. São Paulo: Ed. da Unesp, 1999.

KANT, I. Essai pour introduire en philosophie le concept de grandeur négative. [1763]. Paris: Vrin, 1972. 1989.

. Crítica da razão Pura. [1781]. Lisboa: Fundação Calouste Gulbenkian, . Critique de la raison pratique. [1788]. Paris: PUF, 2000.

LACAN, J. A coisa freudiana. [1956]. In: . Escritos. Rio de Janeiro: J. Zahar, 1966. 27/06/62.

L’identification. [S.1.: s.n.], 1961-62. Seminário inédito. Lição de . O Seminário: angústia. [1962-63]. Rio de Janeiro: J. Zahar, 2005. Livro X.

- O Seminário: o eu na teoria de Freud e na técnica da Psicanálise. [1954-5]. Rio de Janeiro: J. Zahar, 1985. Livro II.

. O Seminário: os quatro conceitos fundamentais da psicanálise. [1964]. Rio de Janeiro: J. Zahar, 1981. Livro XI.

Posição do inconsciente. [1964]. In: . Escritos. Rio de Janeiro: J. Zahar, 1998.

. RSI. [S.l.: s.n.], 1974-5. Seminário inédito. Lição de 21/01/1975.

PHILONENKO, A. L'oeuvre de Kant. [1969]. Paris:Vrin, 1989. t.1.

PUECH, M. Kant et la causalité. Paris: Vrin, 1990.

ZIZEK, S. Metastases of enjoyment: six essays on woman and causality. London: Verso, 1994.

Recebido em: março de 2005 Aceito em: março de 2006 